\title{
Molecular crowding has no effect on the dilution thermodynamics of the biologically relevant cation mixtures
}

\author{
Daria Głogocka ${ }^{1,2}$, Magdalena Przybyło ${ }^{1,2}$ and Marek Langner ${ }^{1,2}$ \\ ${ }^{1}$ Department of Biomedical Engineering, Faculty of Fundamental Problems of Technology, Wrocław University of Technol- \\ ogy, Wybrzeże Wyspiańskiego 27, 50-370 Wrocław, Poland \\ ${ }^{2}$ Lipid Systems Sp. z o.o., ul. Duńska 9, 54-427 Wrocław, Poland
}

\begin{abstract}
The ionic composition of intracellular space is rigorously maintained in the expense of high-energy expenditure. It has been recently postulated that the cytoplasmic ionic composition is optimized so the energy cost of the fluctuations of calcium ion concentration is minimized. Specifically, thermodynamic arguments have been produced to show that the presence of potassium ions at concentrations higher than $100 \mathrm{mM}$ reduce extend of the energy dissipation required for the dilution of calcium cations. No such effect has been measured when sodium ions were present in the solution or when the other divalent cation magnesium was diluted. The experimental observation has been interpreted as the indication of the formation of ionic clusters composed of calcium, chloride and potassium. In order to test the possibility that such clusters may be preserved in biological space, the thermodynamics of ionic mixtures dilution in solutions containing albumins and model lipid bilayers have been measured. Obtained thermograms clearly demonstrate that the energetics of calcium/potassium mixture is qualitatively different from calcium/sodium mixture indicating that the presence of the biologically relevant quantities of proteins and membrane hydrophilic surfaces do not interfere with the properties of the intracellular aqueous phase.
\end{abstract}

Key words: Thermodynamics of ions — Molecular crowding - Membrane crowding - Isothermal titration calorimetry - Calcium intracellular signaling

\section{Introduction}

Ionic homeostasis inside cell is a critical element of proper progression of all its vital functions. The ionic composition of intracellular aqueous phase affects solubility and aggregation state of all molecules filling the cell volume (Hey et al. 2005; Kunz 2010; Huang et al. 2015). Ions also participate in many metabolic processes as necessary cofactors (Murgia et al. 2009; Spitzer and Poolman 2009). Their electrochemical gradients are necessary for the energy and information transformations (Bortner and Cidlowski 2004; Ivannikov et al. 2010). The spatio-temporal distribution of ions is facilitated by an intricate system of fluxes between various compart-

Correspondence to: Daria Głogocka, Department of Biomedical Engineering, Faculty of Fundamental Problems of Technology, Wrocław University of Technology, Wybrzeze Wyspianskiego 27, 50-370 Wroclaw, Poland

E-mail: daria.glogocka@pwr.edu.pl ments driven by dedicated channels, pumps and chelating agents (Boldyrev 1993; Yu 2001; Decrock et al. 2011; Lee et al. 2011; Eisenberg 2013; Chen et al. 2014). Whereas the passive ion flux in the cell is governed by electrochemical gradients, the active transport is associated with energy dissipation. Nearly $70 \%$ of adenosine triphosphate (ATP) in some cells is used to maintain the ionic homeostasis (Ivannikov et al. 2010). There are four main cations present in the cytoplasm: potassium, sodium, magnesium and calcium. The averaged concentrations of monovalent potassium (about $140 \mathrm{mM}$ ) and sodium (about $4 \mathrm{mM}$ ) as well as divalent magnesium $(3 \mathrm{mM})$ are constant in time. Calcium is an unusual cation, which concentration fluctuates between $10^{-10} \mathrm{M}$ and $10^{-4}$ $\mathrm{M}$, serving as a second messenger in intracellular signaling cascades (Landolfi et al. 1998; Michelangeli et al. 2005; Ivannikov et al. 2010). Such large concentration changes require expenditure of large quantities of metabolic energy reaching $17 \%$ of the entire energy dissipated by cells (Eisner et al. 2004; Case et al. 2007; Ivannikov et al. 2010). Recently, we 
have demonstrated that the thermodynamics of the dilution of calcium ions in water is greatly affected by the concentration and type of monovalent cation (Kaczynski et al. 2014). This finding provides the thermodynamic argument for the specific ionic composition of the intracellular space. It has been demonstrated that the thermodynamics of calcium dissolution depends on the combination of ion-water and ion-ion interactions (Landolfi et al. 1998; Arias-Moreno et al. 2010; Liu et al. 2010; Yang et al. 2010). Whereas the dissolution energy of calcium is independent on the sodium chloride concentration, and do not differ significantly from that in water, the effect of the potassium chloride is dramatic. When the potassium quantity rises above the concentration of $100 \mathrm{mM}$ the dilution energy of calcium is dramatically reduced. No such effect is observed for magnesium, the other important divalent cation present in the cytoplasm (Kaczynski et al. 2014). In order to explain the effect the formation of multi-ionic clusters have been postulated (Kaczynski et al. 2014). Such multicomponent ionic clusters would require the sufficient level of hydration, which might be not available in densely packed intracellular space (Spitzer and Poolman 2005; Spitzer and Poolman 2009; Leontidis et al. 2014). In addition, the large quantity of, frequently charged, water-soluble proteins and membrane surfaces might affect organization, dynamics and thermodynamics of ions in the intracellular aqueous phase (Collins 1997; Collins et al. 2007; Ben-Yaakov et al. 2009). Various mixtures of cations have been investigated in order to evaluate the effect of two most numerous components of crowded intracellular environment, hydrophilic proteins and lipid surfaces, on the hydration thermodynamics. For that purpose the watersoluble proteins were modeled with albumins and membrane surfaces were modeled with unilamellar liposomes, both entities in biologically relevant concentrations $50 \mathrm{mg} / \mathrm{ml}$ and $7 \mathrm{mg} / \mathrm{ml}$, respectively (Miyoshi and Sugimoto 2008).

\section{Materials and Methods}

\section{Materials}

Bovine serum albumin (BSA $\geq 98.0 \%$ ) and HEPES (4-(2-hydroxyethyl)-1-piperazineethanesulfonic acid) buffer were obtained from Sigma-Aldrich (Poznan, Poland), calcium chloride, propylene glycol and sodium chloride were purchased from Chempur (Piekary Slaskie, Poland) and potassium chloride was obtained from $\mathrm{POCH}$ (Gliwice, Poland), EggPC 90G from Lipoid GmbH (Ludwigshafen, Germany). All chemicals were of analytical grade and used without further purification. $50 \mathrm{mM}$ HEPES buffer $(\mathrm{pH}=$ 7.4) was prepared using fresh deionized water (conductivity $<2 \mu \mathrm{S}$ ). All solution containing mixtures of salts were tested for the presence of precipitation using the dynamic light scattering technique. In all cases no particulates larger than $2 \mathrm{~nm}$ were detected.

\section{Liposomes preparation}

EggPC at concentration $45 \%(\mathrm{w} / \mathrm{w})$ was dissolved in propylene glycol and incubated for $24 \mathrm{~h}$ at $60^{\circ} \mathrm{C}$. The addition of $50 \mathrm{mM}$ HEPES buffer was followed by further incubation for $24 \mathrm{~h}$ at $60^{\circ} \mathrm{C}$ to ensure the complete lipid hydration. Next, lipid suspension was extruded 5 times through polycarbonate membrane filters (Whatman, UK). Liposomes were diluted with buffer so that the final concentration of lipid was $7 \mathrm{mg} / \mathrm{ml}$. Size of liposomes was measured using Dynamic Light Scattering (DLS) technique (NanoSizer, Malvern GB). In order to measure the effect of the osmotic pressure difference, caused by high salt concentration, on the liposomes size distribution, the DLS experiment was performed at the end of each titration. No significant change was observed (results not shown).

\section{Isothermal titration calorimetry (ITC) measurements}

Sample degassing for 30 minutes preceded each titration experiment. Calorimetric measurements were performed using Thermal Activity Monitor TAM III, equipped with isothermal titration unit (TA Instruments, New Castle, USA). Measurement cell was filled with $800 \mu \mathrm{l}$ of BSA buffered solution $(50 \mathrm{mg} / \mathrm{ml})$, liposomes buffered solution $(7 \mathrm{mg} / \mathrm{ml})$ or buffer solution alone. Solutions from syringe were added into cell in a series of $10 \mu$ injections. Each experiment was preceded with a $1 \mu$ injection, which was neglected in the subsequent analysis. The duration of each injection was $10 \mathrm{~s}$ and the delay time between injections $1500 \mathrm{~s}$. Experiments were carried out at $25.0^{\circ} \mathrm{C}$. In the experiment buffered solutions of $\mathrm{CaCl}_{2}, \mathrm{KCl}, \mathrm{NaCl}$ or their mixtures were titrated into the cell. Concentration of each salt in the mixture was $1.5 \mathrm{M}$. This ensures that the final concentration of salts in the cell reaches the physiological values. Concentration of BSA and lipids in measurement cell were also selected based on physiological values (Chtterjea and Shinde 2012). Heat of the dilution was calculated from thermograms as an area under peaks expressed in Joules. Positive or negative heat flow indicated an exothermic or endothermic process, respectively. All experiment presented in the paper were carried in triplicates using different preparations of proteins or liposomes. Control experiments were performed in duplicates.

\section{Results and Discussion}

The ionic composition of the cell interior is tightly controlled and meticulously maintained despite high-energy 
cost. Whereas the concentrations of most intracellular free ions are invariant in time, the concentration of calcium varies widely by orders of magnitudes facilitating the information transfer through cytoplasm (Cheng and Lederer 2008). These fluctuations, in addition to the maintenance of trans-membrane gradients, increase the amount of energy required to sustain the intracellular ionic homeostasis (Ivannikov et al. 2010). The energy required for the sequential release and removal of calcium ions from cytoplasm depends on the difference of respective energetic states. The energetics of calcium ions in the cytoplasmic aqueous phase is affected, as demonstrated elsewhere, by its ionic composition (Kaczynski et al. 2014). Specifically, the type of monovalent cation present in the solution changes the dilution energetics not only quantitatively but also qualitatively, specifically the dilution of calcium mixed with potassium is an exothermic process but, when potassium is replaced with sodium, the dilution becomes endothermic. Based on this observation it has been postulated that ions in aqueous phase form ionic clusters, which may dramatically change the thermodynamic properties of the solution. Ionic clusters are attractive concepts, which offers straightforward explanation, albeit not confirmed by other experimental evidences, of differences between dilution thermodynamics of various ionic mixtures (Kaczynski et al. 2014). Data presented previously have been carried out using biologically relevant concentration of ions but the experimental model has not accounted for the crowding effect produced by high concentrations of proteins and membranes. The cell volume is a maze of aqueous compartments packed with water-soluble proteins (proteins occupy about $40 \%$ of cell volume) bordered by variety of membrane surfaces (Chandler 2005; Chtterjea and Shinde 2012). In such an environment the existence of intracellular "bulk" water is unlikely and the effect of various surfaces on distribution of ions is likely. The possible effect of macromolecular and membrane crowding on the structure and dynamics of aqueous phase leads to the model, which treats the "aqueous phase" in cell as a structured mixture of water molecules, ions and small hydrophilic compounds (Spitzer and Poolman 2005, 2009; Leontidis et al. 2014). Despite the crowded conditions and low water activity the cell interior is still capable to provide conditions for the propagation of intracellular signals especially those based on fluctuations of calcium concentration (Taheri-Araghi and Ha 2010; Szekely et al. 2011; Thurley et al. 2012; Wakai and Fissore 2013; Swietach et al. 2015). Calcium is continuously released and reloaded into intracellular stores during the signaling events (Joseph et al. 2014). The calcium signal can last from seconds to hours therefore the intracellular aqueous compartments with elevated calcium concentration should not affect the hydrophilichydrophobic balance, which maintain the stability of concentrated intracellular suspension of proteins and membranes (Thurley et al. 2012; Joseph et al. 2014). We have previously demonstrated that the dissolution thermodynamics of mixtures of calcium and potassium chlorides indicate that the two cations combined with chloride ions may form stable clusters, which do not disintegrate upon dilution (Kaczynski et al. 2014). It has also been also observed that the thermodynamics of ionic mixture dilution is mainly controlled by the potassium concentration regardless on the quantity of calcium present in the
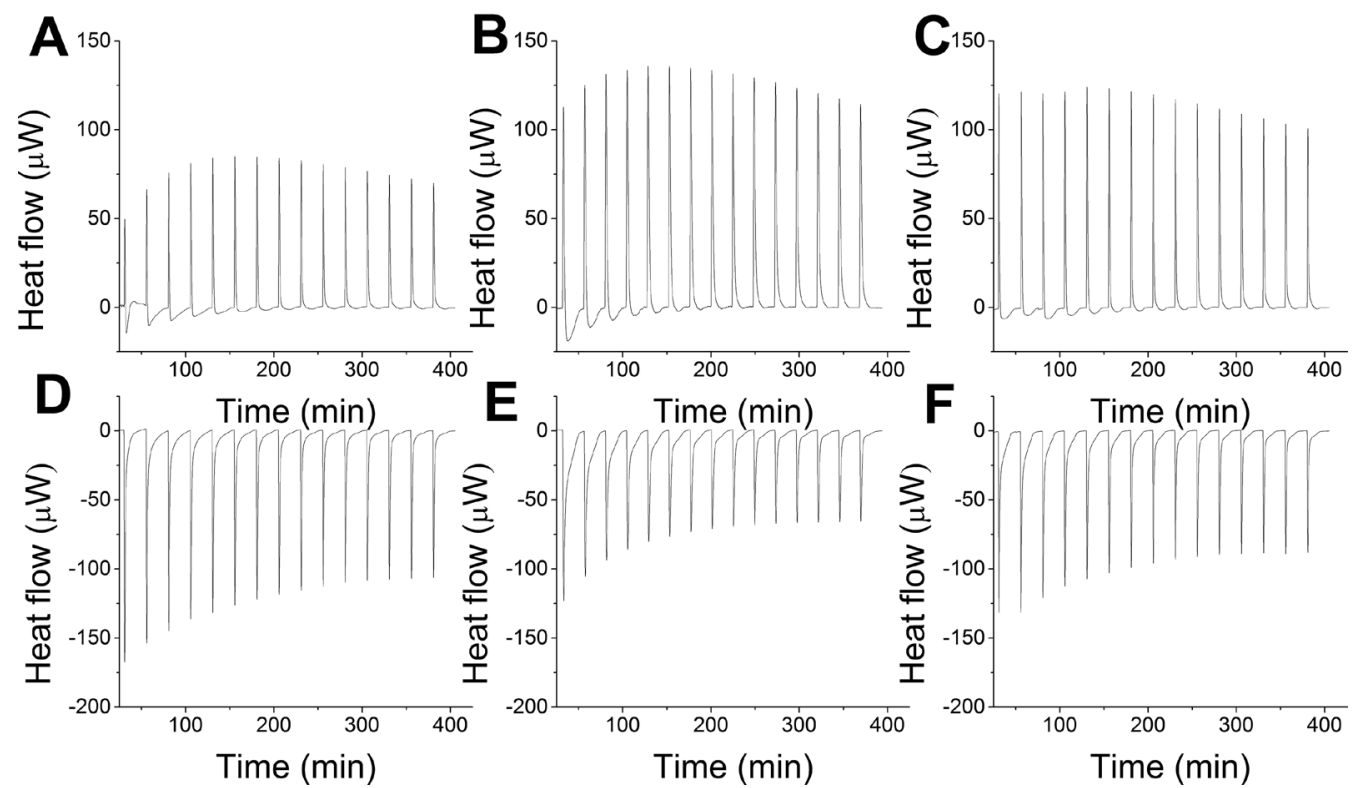

Figure 1. Thermograms of $50 \mathrm{mg} / \mathrm{ml}$ albumin solution (A and $\mathbf{D}), 7$ $\mathrm{mg} / \mathrm{ml}$ lipid vesicles suspension (B and $\mathbf{E})$ and buffer ( $\mathbf{C}$ and $\mathbf{F})$, titrated with $\mathrm{KCl}: \mathrm{CaCl} 2$ (1:1) mixture (A, B, C) and $\mathrm{NaCl}: \mathrm{CaCl} 2(1: 1)$ mixture (D, E, F). 

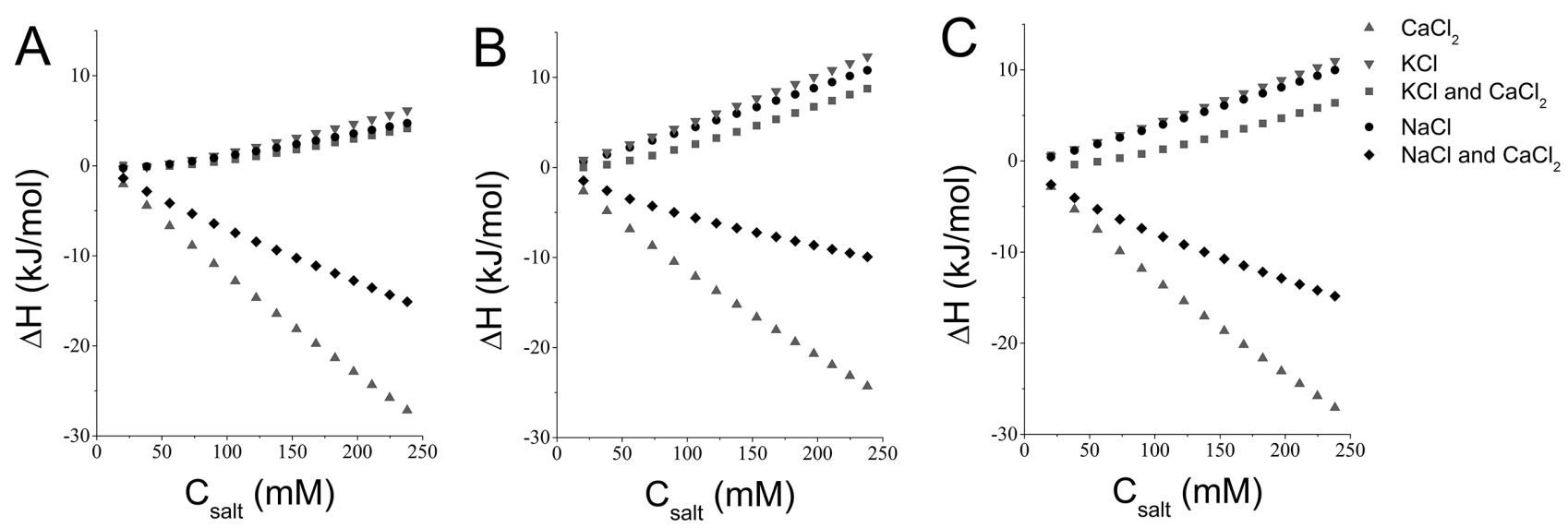

Figure 2. Cumulative enthalpy changes $(\Delta \mathrm{H})$ calculated from the dilution experiments carried out for selected salt solutions as a function of the salt concentration $\left(\mathrm{C}_{\text {salt }}\right)$ in the reaction cell in the presence of BSA $(\mathbf{A})$, liposomes $(\mathbf{B})$ and buffer alone $(\mathbf{C})$. The dilution of $\mathrm{KCl}: \mathrm{CaCl}_{2}$ (1:1) mixture, $\mathrm{NaCl}: \mathrm{CaCl}_{2}(1: 1)$ mixture.

mixture what substantiate the assumption of the presence of ionic clusters. However, the crowded cell interior may interfere with dilution thermodynamic by altering local ionic composition. Surfaces of membranes and/or proteins may alter distribution of ions in the adjacent aqueous phases (Pollack 2003; Zhang and Cremer 2006; Porasso and Cascales 2009; Parsegian and Zemb 2011; Parsons et al. 2011; Przybylo et al. 2014). In order to determine the effect of water-soluble proteins and neutral membranes

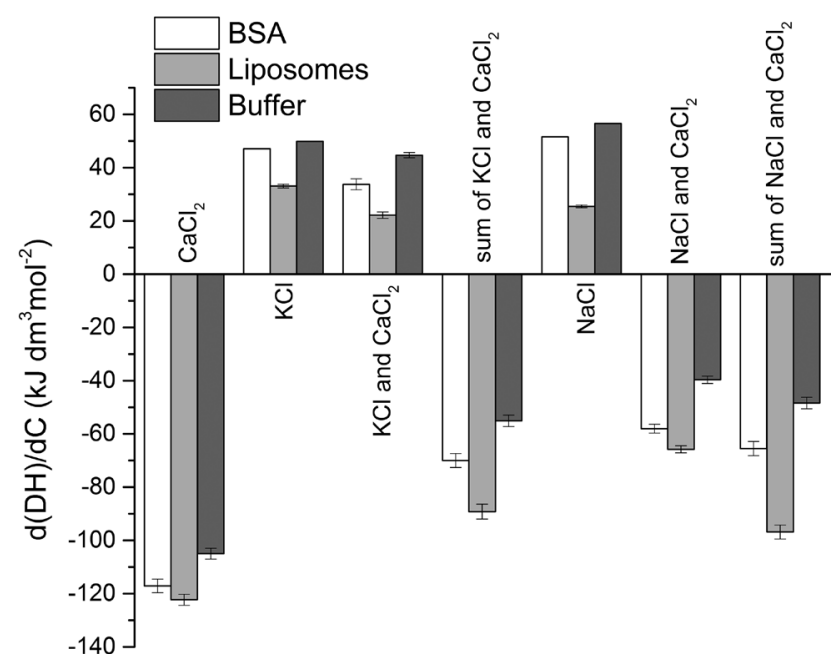

Figure 3. The slopes of the linear dependence of the cumulative enthalpies $(\mathrm{d}(\Delta \mathrm{H} / \mathrm{dC})$ on ions concentration as determined in the dilution experiments $50 \mathrm{mg} / \mathrm{ml}$ albumin solution and $7 \mathrm{mg} /$ $\mathrm{ml}$ liposome suspension. The calculated values of the slopes for ionic mixtures, expressed as a sum of enthalpies obtained in the dilution experiments performed for each salt alone, are presented for comparison. on the dilution thermodynamics, the calorimetric experiment has been performed at the presence of biologically relevant concentrated protein solution and lipid vesicles suspension. The concentrated solution of albumin (50 mg/ $\mathrm{ml}$ ) was used as a model of intracellular aqueous space crowded with proteins, whereas concentrated suspension of lipid vesicles $(7 \mathrm{mg} / \mathrm{ml}$ ) was used to model the effect of membrane surfaces on ions dissolved in the aqueous phase. Figure 1 shows thermograms of two salts mixtures $\mathrm{NaCl}: \mathrm{CaCl}_{2}$ (1:1) and $\mathrm{KCl}: \mathrm{CaCl}_{2}$ (1:1) titrated into buffer or concentrated albumin or membrane solutions.

Panel $\mathrm{C}$ and $\mathrm{F}$ on Figure 1 show that when the buffer was titrated with mixtures of $\mathrm{KCl}: \mathrm{CaCl}_{2}(1: 1)$ and $\mathrm{NaCl}: \mathrm{CaCl}_{2}$ $(1: 1)$ qualitatively different thermograms were acquired. Whereas the dilution process of $\mathrm{CaCl}_{2}: \mathrm{KCl}$ mixture is endothermic the dilution of $\mathrm{CaCl}_{2}: \mathrm{NaCl}$ mixture is exothermic. The explanation of this difference has been offered previously (Kaczynski et al. 2014). Assuming that mixtures of $\mathrm{CaCl}_{2}$ and $\mathrm{NaCl}$ salts produce homogenous solvents their dilution thermograms can be approximated with the sum of dilution enthalpies of each salts individually. The situation is different when mixtures of $\mathrm{CaCl}_{2}$ and $\mathrm{KCl}$ are diluted. The quantity of energy released in this case does not differ significantly from the energy released when the $\mathrm{KCl}$ solution is diluted alone, indicating that in this case the solution is not homogeneous. The effect was explained by the proposition that the solution produced by mixtures of $\mathrm{CaCl}_{2}$ and $\mathrm{KCl}$ salts contain dilution resistant clusters of interacting ions. Panel C in Figure 2 and Figure 3 demonstrate the difference between the two mixtures of salts. It has been proposed previously that stable ionic $\mathrm{Ca}^{2+}: \mathrm{Cl}^{-}: \mathrm{K}^{+}$clusters are formed in sufficiently high potassium concentrations preventing the change of $\mathrm{Ca}^{2+}$ hydration upon dilution (Kaczynski et al. 2014). 
In order to highlight differences between titration experiments plots of cumulative enthalpy changes are fitted with linear function and the slope is then calculated and presented in Figure 3.

Figure 3 quantitatively summarizes results obtained for each titrant, expressed as abovementioned slopes, derived using the regression analysis, for ions and their mixtures titrated into buffer, protein solution or lipid suspension. Data presented in Figure 3 shows that energetics of $\mathrm{CaCl}_{2}: \mathrm{KCl}(1: 1)$ dilution with the buffer, albumin solution or suspension of liposomes is qualitatively similar. This indicates that postulated ionic clusters remain intact in the aqueous phase at biologically relevant concentrations of water-soluble proteins and lipid membranes therefore supporting the preposition that ionic clusters containing $\mathrm{Ca}^{2+}$ and $\mathrm{K}^{+}$cations may reduce the energy cost of the intracellular signaling mediated by spatio-temporal fluctuations of $\mathrm{Ca}^{2+}$ ion concentration. No such effect is observed when mixtures of $\mathrm{Ca}^{2+}$ and $\mathrm{Na}^{+}$cations are used. Despite the lack of qualitative effects of proteins or membranes, on the overall character of the dilution thermodynamics of salts and their mixtures there are some quantitative differences. The presence of albumin and lipid membrane results with the elevated enthalpies of calcium dissolutions by $11 \%$ and $17 \%$, respectively. This indicates that there are some interactions between calcium and/or chlorine ions with proteins and lipid surfaces. This result agrees with other studies, which have demonstrated that polyions bind with variety of compounds and structures (Ahyayauch et al. 2009; Arias-Moreno et al. 2010; Morton et al. 2010; Parsons et al. 2011). The effect is bigger when lipid bilayers are present in the solution. Analysis of $\mathrm{NaCl}$ and $\mathrm{KCl}$ dilutions demonstrate that the effect of protein on the two ions is small ( $8 \%$ and $5 \%$, respectively) as compared to the effect of lipid surfaces. The effect of lipid surface on the sodium dilution (changed by $55 \%$ ) is significantly stronger then on the potassium dilution (changed by $34 \%$ ) showing that interaction between sodium and lipid surfaces is significant. The result agrees with data presented in literature (Vlachy et al. 2009; Yang et al. 2010; Klasczyk et al. 2010; Przybylo et al. 2014).

When mixtures of potassium and calcium are diluted in the presence of albumins and lipid membranes, the absolute value of dilution enthalpy is reduced in a meaner similar to that of potassium chloride alone showing that ionic environment make calcium unavailable for interaction with crowding agents. When the mixture of sodium and calcium is added to proteins and membranes the resulting dilution enthalpy is elevated by $46 \%$ and $66 \%$, respectively. This result shows that the two cations interact with both proteins and membranes with little mutual interferences.

There are two factors, which need to be taken into account when analyzing phenomena occurring in crowded and/or concentrated solutions. First, ions are different with the respect to their charge, surface charge density and hydration what affects their solubility and, as demonstrated previously, propensity to form ionic complexes (Collins 1995, 1997; Collins et al. 2007). The ionic complexes may alter the Debye effect, especially at charged endomembrane surfaces (Langner and Kubica 1999; Vlachy et al. 2009; Yang et al. 2010). In this case the main assumptions of the GouyChampman theory may not be satisfied limiting dramatically applicability of the theory when intracellular processes are analyzed (Ben-Yaakov et al. 2011). Any local alteration of ionic composition may change hydrophobic/hydrophilic balance of surrounding macromolecules leading to their precipitation or aggregation as dramatically demonstrated by Hofmeister effect (Baldwin 1996; Kunz et al. 2004; Hey et al. 2005). Whereas the effect of monovalent ions on macromolecules solubility and/or propensity to aggregate is relatively weak, the effect of divalent ions can be dramatic. For example, calcium may induce fusion of negatively charged membranes present in high quantities in the cell cytoplasm (Michelangeli et al. 2005; Boettcher et al. 2011; Naranjo and Mellstrom 2012). The presence of ionic clusters containing calcium may contribute to the preservation of the electrostatic balance when the calcium concentration rises upon cell stimulation therefore ensuring the topological stability of endomembrane systems. The calcium release may induce intracellular molecular rearrangements, which may result from direct interaction of calcium ion with proteins and/ or membranes triggered by the altered intracellular ionic composition (Tojyo et al. 2014). Data presented in the paper shows that the thermodynamics of ionic mixtures dilution is not qualitatively altered by the presence of interfaces presented by membranes and proteins showing that underlying molecular processes are likely to be preserved in a crowded intracellular environment.

\section{Conclusions}

The ionic composition of the cytoplasm determines its stability (hydrophobic/hydrophilic balance) and facilitates the transmission of signals through the cell volume. Whereas the major elements of the ionic homeostasis are qualitatively and quantitatively well characterized, the exact ionic composition of cell has not been convincingly justified. Recently, it has been proposed that the specific composition of the cellular space is determined by the thermodynamics of the collective hydration of ions. It has been demonstrated that the thermodynamics of dilution of ion mixtures dramatically depends on their ionic composition. Specifically, the dilution of calcium and potassium chlorides mixture is qualitatively different from all other mixtures. It has been speculated that the difference is a result of ionic 
clusters formation, which may ensure stable level of calcium hydration regardless on their concentration. The significance of such ionic clusters in biological space filled with tightly packed soluble proteins and membranes depend on the cluster stability at the presence of various hydrated surfaces. Results of calorimetric experiments shown in the paper demonstrate that the presence of biologically relevant density of hydrophilic proteins and lipid bilayers do not influence the dilution thermodynamics of ionic mixtures containing calcium cation. This result shows that the ionic composition of the cytoplasm may play critical role in the stability of crowded biological space by ensuring the solubility of various components of cell volume.

Acknowledgements. The study was possible thanks to the financial support from the National Centre of Sciences Grant no. N N302 663740 and the Fellowship co-financed by European Union within European Social Fund and Institute of Biomedical Engineering and Instrumentation at Wroclaw University of Technology.

\section{References}

Ahyayauch H., Arana G., Sot J., Alonso A., Goni F. M. (2009) Calcium inhibits diacylglycerol uptake by serum albumin. Biochim. Biophys. Acta 1788, 701-707 https://doi.org/10.1016/j.bbamem.2008.11.016

Arias-Moreno X., Cuesta-Lopez S., Millet O., Sancho J., VelazquezCompoy A. (2010): Thermodynamics of protein-cation interaction: $\mathrm{Ca}+2$ and $\mathrm{Mg}+2$ binding to the fifth binding module of the LDL receptor. Proteins 78, 950-961 https://doi.org/10.1002/prot.22619

Baldwin R. L. (1996): How Hofmeister ion interactions affect protein stability. Biophys. J. 71, 2056-2063 https://doi.org/10.1016/S0006-3495(96)79404-3

Ben-Yaakov D., Andelman D., Harries D., Podgornik R. (2009): Ions in mixed dielectric solvents: density profiles and osmotic pressure between charged interfaces. J. Phys. Chem. B, 113, 6001-6011 https://doi.org/10.1021/jp9003533

Ben-Yaakov D., Andelman D., Podgornik R., Harries D. (2011): Ionspecific hydration effects: Extending the Poisson-Boltzmann theory. Current opinion in colloid and interface science, 16, $542-550$ https://doi.org/10.1016/j.cocis.2011.04.012

Boettcher J. M., Davis-Harrison R. L., Clay M. C., Nieuwkoop A. J., Ohkubo Y. Z., Tajkhorshid E., Morrissey J. H., Rienstra C. M. (2011): Atomic view of calcium-induced clustering of phosphatidylserine in mixed lipid bilayers. Biochemistry 50, 2264-2273 https://doi.org/10.1021/bi1013694

Boldyrev A. A. (1993): Functional-activity of $\mathrm{Na}+\mathrm{K}+$-pump in normal and pathological tissues. Mol. Chem. Neuropathol. 19, 83-93 https://doi.org/10.1007/BF03160170
Bortner C. D., Cidlowski J. A. (2004): The role of apoptotic volume decrease and ionic homeostasis in the activation and repression of apoptosis. Eur. J. Physiol. 448, 313-318 https://doi.org/10.1007/s00424-004-1266-5

Case R. M., Eisner D., Gurney A., Jones O., Muallem S., Verkhratsky A. (2007): Evolution of calcium homeostasis: from birth of the first cell to an omnipresent signalling system. Call Calcium 42, 345-350 https://doi.org/10.1016/j.ceca.2007.05.001

Chandler D. (2005): Interfaces and the driving force of hydrophobic assembly. Nature 437, 640-647 https://doi.org/10.1038/nature04162

Chen D. D., Yu S. P., Wei L. (2014): Ion channels in regulation of neuronal regenerative activities. Transl. Stroke Res. 5, 156-162 https://doi.org/10.1007/s12975-013-0320-Z

Cheng H., Lederer W. J. (2008): Calcium sparks. Physiol. Rev. 88, 1491-1545 https://doi.org/10.1152/physrev.00030.2007

Chtterjea M. N., Shinde R. (2012): Textbook of medical biochemistry. New Delhi, Jaypee Brothers Medical Publications https://doi.org/10.5005/jp/books/11486

Collins K. D. (1995): Sticky ions in biological systems. Proc. Natl. Acad. Sci. USA 92, 5553-5557 https://doi.org/10.1073/pnas.92.12.5553

Collins K. D. (1997): Charge density-dependent strength of hydration and biological structure. Biophys. J. 72, 65-76 https://doi.org/10.1016/S0006-3495(97)78647-8

Collins K. D., Neilson G. W., Enderby J. E. (2007): Ions in water: characterizing the forces that control chemical processes and biological structure. Biophys. Chem. 128, 95-104 https://doi.org/10.1016/j.bpc.2007.03.009

Decrock E., Vinken M., Bol M., D'Herde K., Rogiers V., Vandenabeele P., Krysko D. V., Bultynck G., Leybaert L. (2011): Calcium and connexin-based intercellular communication, a deadly catch? Cell Calcium 50, 310-321 https://doi.org/10.1016/j.ceca.2011.05.007

Eisenberg B. (2013): Ionic interactions are everywhere. Physiology 28, 28-38 https://doi.org/10.1152/physiol.00041.2012

Eisner D. A., Diaz M. E., Li Y., O'Neill S. C., Trafford A. W. (2004): Stability and instability of tegulation of intracellular calcium. Exp. Physiol. 90, 3-12 https://doi.org/10.1113/expphysiol.2004.029231

Hey M. J., Jackson D. P., Yan H. (2005): The salting-out effect and phase separation in aqueous solutions of electrolytes and poly(ethylene glycol). Polymer 46, 2567-2572 https://doi.org/10.1016/j.polymer.2005.02.019

Huang L. Q., Liu X. R., Cheng B. A., Huang K. (2015): How our bodies fight amyloidosis: Effects of physiological factors on pathogenic aggregation of amyloidogenic proteins. Arch. Biochem. Biophys. 568, 46-55 https://doi.org/10.1016/j.abb.2015.01.007

Ivannikov M. V., Sugimori M., Llinas R. R. (2010): Cacium clearance and its energy requirements in cerebellar neurons. Cell Calcium 47, 507-513 https://doi.org/10.1016/j.ceca.2010.04.004

Joseph N., Reicher B., Barda-Saad M. (2014): The calcium feedback loop and $\mathrm{T}$ cell activation: How cytoskeleton networks 
control intracellular calcium flux. Biochim. Biophys. Acta 1838, 557-568 https://doi.org/10.1016/j.bbamem.2013.07.009

Kaczynski M., Borowik T., Przybylo M., Langner M. (2014): Dilution thermodynamics of the biologically relevant cation mixtures. Thermochimica Acta 575, 269-275 https://doi.org/10.1016/j.tca.2013.10.019

Klasczyk B., Knecht V., Lipowsky R., Dimova R. (2010): Interactions of alkali metal chlorides with phosphatidylcholine vesicles. Langmuir 26, 18951-18958 https://doi.org/10.1021/la103631y

Kunz W. (2010): Specific ion effects in colloidal and biological systems. Curr. Opin. Colloid Interface Sci. 15, 34-39 https://doi.org/10.1016/j.cocis.2009.11.008

Kunz W., Lo-Nostro P., Ninham B. W. (2004): The present state of affairs with Hofmeister effects. Curr. Opin. Colloid Interface Sci. 9, 1-18 https://doi.org/10.1016/j.cocis.2004.05.004

Landolfi B., Curci S., Debellis L., Pozzan T., Hofer A. M. (1998): $\mathrm{Ca} 2+$ homeostasis in the agonist-sensitive internal store: functional interactions betwen mitochondria and the ER measured in situ in intact cells. J. Gen. Physiol. 142, 1235-1243 https://doi.org/10.1083/jcb.142.5.1235

Langner M., Kubica K. (1999): The electrostatics of lipid surfaces. Chem. Phys. Lipids 101, 3-35 https://doi.org/10.1016/S0009-3084(99)00052-3

Lee J. M., Davis F. M., Roberts-Thomson S. J., Monteith G. R. (2011): Ion channels and transporters in cancer. 4. Remodeling of $\mathrm{Ca} 2+$ signaling in tumorigenesis: role of $\mathrm{Ca} 2+$ transport. Am. J. Physiol. Cell Physiol. 301, C969-976 https://doi.org/10.1152/ajpcell.00136.2011

Leontidis E., Christoforou M., Georgiou C., Delclos T. (2014): The ion-lipid battle for hydration water and interfacial sites at soft-matter interfaces. Curr. Opin. Colloid Interface Sci. $19,2-8$ https://doi.org/10.1016/j.cocis.2014.02.003

Liu X., Lu X., Meijer E. J., Wang R. (2010): Hydration mechanisms of $\mathrm{Cu} 2+$; tetra-, penta- or hexa-coordinated? Phys. Chem. Chem. Phys. 12, 10801-10804 https://doi.org/10.1039/c001916j

Michelangeli F., Ogunbayo O. A., Wootton L. L. (2005): A plethora of interacting organellar $\mathrm{Ca} 2+$ stores. Curr. Opin. Cell Biol. 17, 135-140 https://doi.org/10.1016/j.ceb.2005.01.005

Miyoshi D., Sugimoto N. (2008): Molecular crowding effects on structure and stability of DNA. Biochimie 90, 1040-1051 https://doi.org/10.1016/j.biochi.2008.02.009

Morton A. R., Garland J. S., Holden R. M. (2010): Is the calcium correct? Measuring serum calcium in dialysis patients. Semin. Dial. 23, 283-289 https://doi.org/10.1111/j.1525-139X.2010.00735.x

Murgia M., Giorgi C., Pinton P., Rizzuto R. (2009): Controlling metabolism and cell death: at the heart of mitochondrial calcium signalling. J. Mol. Cell. Cardiology 46, 781-788 https://doi.org/10.1016/j.yjmcc.2009.03.003

Naranjo J. R., Mellstrom B. (2012): Ca2+-dependent transcriptional control of Ca2+ homeostasis. J. Biol. Chem. 287, 31674-31680 https://doi.org/10.1074/jbc.R112.384982
Parsegian V. A., Zemb T. (2011): Hydration forces: Observations, explanations, expectations, questions. Curr. Opin. Colloid Interface Sci. 16, 618-624

https://doi.org/10.1016/j.cocis.2011.06.010

Parsons D. F., Bostrom M., Lo Nostro P., Ninham B. W. (2011): Hofmeister effects: interplay of hydration, nonelectrostatic potentials, and ion size. Phys. Chem. Chem. Phys. 13, 1235212367 https://doi.org/10.1039/c1cp20538b

Pollack G. H. (2003): The role of aqueous interfaces in the cell. Adv. Colloid Interface Sci. 103, 173-196 https://doi.org/10.1016/S0001-8686(02)00095-7

Porasso R. D., Cascales J. J. L. (2009): Study of the effect of Na+ and $\mathrm{Ca} 2+$ ion concentration on the structure of an asymmetric DPPC/DPPC+DPPS lipid bilayer by molecular dynamics simultion. Colloids Surf B Biointerfaces 73, 42-50 https://doi.org/10.1016/j.colsurfb.2009.04.028

Przybylo M., Drabik D., Łukawski M., Langner M. (2014): Effect of monovalent anions on water transmembrane transport. J. Phys. Chem. B 118, 11470-11479 https://doi.org/10.1021/jp505687d

Spitzer J., Poolman B. (2009): The role of biomacromolecular crowding, ionic strength, and physicochemical gradients in the complexities of life's emergence. Microbiol. Mol. Biol. Rev. $73,371-388$ https://doi.org/10.1128/MMBR.00010-09

Spitzer J. J., Poolman B. (2005): Electrochemical structure of the crowded cytoplasm. Trends Biochem. Sci. 30, 536-541 https://doi.org/10.1016/j.tibs.2005.08.002

Swietach P., Spitzer K., Vaughan-Jones R. D. (2015): Na+ ions as spatial intracellular messengers for co-ordinating $\mathrm{Ca} 2+$ signals during $\mathrm{pH}$ heterogeneity in cardiomyocytes. Cardiovasc. Res. 105, 171-181 https://doi.org/10.1093/cvr/cvu251

Szekely O., Steiner A., Szekely P., Amit E., Asor R., Tamburu C., Raviv U. (2011): The structure of ions and zwitterionic lipids regulates the charge of dipolar membranes. Langmuir 27, 7419-7438 https://doi.org/10.1021/la200264s

Taheri-Araghi S., Ha B. Y. (2010): Electrostatic bending of lipid membranes: how are lipid and electrostatic properties interrelated? Langmuir 26, 14737-14746 https://doi.org/10.1021/la102052r

Thurle K., Skupin A., Thul R., Falcke M. (2012): Fundamental properties of Ca2+ signals. Biochim. Biophys. Acta 1820, 1185-1194 https://doi.org/10.1016/j.bbagen.2011.10.007

Tojyo Y., Morita T., Nezu A., Tanimura A. (2014): Key components of store-operated $\mathrm{Ca} 2+$ entry in non-excitable cells. J. Pharmacol. Sci. 125, 340-346 https://doi.org/10.1254/jphs.14R06CP

Vlachy N., Jagoda-Cwiklik B., Vacha R., Touraud D., Jungwirth P., Kunz W. (2009): Hofmeister series and specific interactions of charged headgroups with aqueous ions. Adv. Colloid Interface Sci. 146, 42-47 https://doi.org/10.1016/j.cis.2008.09.010

Wakai T., Fissore R. A. (2013): Ca2+ homeostasis and regulation of ER Ca2+ in mammalian oocytes/eggs. Cell Calcium 53, 63-67 https://doi.org/10.1016/j.ceca.2012.11.010 
Yang H., Xu Y., Gao Z., Mao Y., Du Y., Jiang H. (2010): Effects of $\mathrm{Na}+, \mathrm{K}+, \mathrm{Ca} 2+$ on the structures of anionic lipid bilayers and biological implication. J. Phys. Chem. B 114, 16978-16988 https://doi.org/10.1021/jp1091569

Yu S. P., Canzoniero L. M. T., Choi D. W. (2001): Ion homeostasis and apoptosis. Curr. Opin. Cell Biol. 13, 405-411 https://doi.org/10.1016/S0955-0674(00)00228-3
Zhang Y., Cremer P. S. (2006): Interactions between macromolecules and ions: the Hofmeister series. Curr. Opin. Chem. Biol. 10, 658-663

https://doi.org/10.1016/j.cbpa.2006.09.020

Received: February 10, 2016

Final version accepted: July 1, 2016

First published online: February 20, 2017 